\title{
An updated review of interactions of statins with antibacterial and antifungal agents
}

\author{
Khalid Eljaaly ${ }^{1,2 *}$ and Samah Alshehri ${ }^{1,2}$ \\ ${ }^{1}$ Department of Clinical Pharmacy, King Abdulaziz University, Jeddah, Saudi Arabia \\ ${ }^{2}$ College of Pharmacy, University of Arizona, Tucson, AZ
}

\begin{abstract}
Numerous antimicrobial agents interact with statins. It is important to prevent these drug interactions and resulting statin toxicity and/or reduced efficacy. We review and highlight major drug-drug interactions between statins and antibacterial and antifungal agents; interactions with antiviral agents were not considered. Daptomycin interacts with statins via additive skeletal muscle toxicity. One possibility is to discontinue statins during daptomycin therapy, though no retrospective studies to date have shown a statistically significant elevation of adverse outcome risk. Multiple doses of rifampin induce cytochrome P450 (CYP), particularly $3 \mathrm{~A} 4$ and $2 \mathrm{C} 9$, resulting in reduced systemic exposures to all statins, except rosuvastatin, for which the response was variable. Macrolide antibiotics are inhibitors of CYP3A4 and organic anion-transporting polypeptide-1B1. Azithromycin has the fewest drug interactions, while clarithromycin and erythromycin increase systemic exposure to all statins except rosuvastatin and fluvastatin. Azole antifungals are CYP450 inhibitors. Itraconazole and posaconazole are strong CYP3A4 inhibitors and mainly affect simvastatin, lovastatin, and atorvastatin, while fluconazole is an inhibitor of CYP2C9 and potentially CYP2C19 and mainly affects fluvastatin; however, risk cannot be ruled out with rosuvastatin.
\end{abstract}

\section{Introduction}

Statins (hydroxymethylglutaryl-CoA reductase inhibitors) are commonly used lipid-lowering medications that once started are typically administered for the life of the patient. Given that most people receive antimicrobial agents during their lifetimes, the coadministration of statins and antimicrobial agents is common. Statins are considered relatively safe; however, they can cause life-threatening rhabdomyolysis with acute kidney insufficiency (AKI). These effects may be aggravated by high doses and interactions with other drugs that result in high systemic exposure, measured by the area under the plasma drug concentration-time curve (AUC) [1,2]. Therefore, it is important to be proactive and intervene when necessary by changing the interacting drugs, doses, and/or monitoring the patient more closely.

Metabolic drug-drug interactions are caused by inhibition or stimulation of cytochrome P450 (CYP450) hepatic metabolizing enzymes and/or drug transporters. Nonetheless, the AUC of most statins increases considerably despite not being metabolized by CYP450. Rhabdomyolysis incidence with the use of statins metabolized by CYP3A4 is approximately 5 times higher than with the use of the non-CYP3A4metabolized statins [1,2].Patients receiving statins should be closely monitored for symptoms of skeletal muscle toxicity and increases in serum creatinine kinase (CK) concentrations. In addition, statin package inserts occasionally give clear recommendations on how to respond to a statin-antimicrobial interaction; these recommendations are summarized in Table 1. It should be noted that there are limitations with the drug interaction studies and the results of one study might not necessary be generalizable. The pharmacokinetic (PK) studies typically include healthy volunteers, whereasgeneral population could have several comorbidities that might affect the PKs of statins or increase the risk of adverse events. The objective of this review is to highlight the clinically relevant drug-drug interactions between statins and antibacterial/antifungal agents. In this review, statins were the object drugs and antibacterial/antifungal agents were the precipitant drugs. Antiviral agents were excluded from this study.

\section{Statin metabolism}

There are various mechanisms by which statins can interact with other medications. Numerous statins are substrates of CYP450, organic anion-transporting polypeptide (OATP)-1B1/3, and other transporters and metabolizing enzymes [3-5].Both simvastatin and lovastatin are prodrugs that require activation to simvastatin acid and lovastatin acid, respectively. Simvastatin and lovastatin are the principal CYP3A4 substrates, followed by atorvastatin [5-8], while fluvastatin and rosuvastatin is a CYP2C 9 substrate $[9,10]$. Pravastatin, and pitavastatin are not substrates of CYP450 [11,12].

\section{Literature review}

A systematic search of PubMed was conducted without date or language restrictions through 2/3/2017. The Medical Subject Headings $(\mathrm{MeSH})$ terms used were "Anticholesteremic Agents" and "AntiInfective Agents", excluding "Antiviral agents". PK and observational studies on drug-drug interactions between statins and antibacterial/

*Correspondence to: Khalid Eljaaly, Department of Clinical Pharmacy, King Abdulaziz University, P.O. Box 80200, Jeddah, postal code 21589, Saudi Arabia, Tel: +1(857) 272-2994; Fax: +12 (9666400000). ext: 20675; E-mail: keljaaly@kau. edu.sa or eljaaly@pharmacy.arizona.edu

Key words: statin, antimicrobial, antibiotic, antifungal, drug interaction

Received: February 19, 2017; Accepted: February 28, 2017; Published: March 03,2017 
Table 1. Manufacturer recommendations and AUC changes for selected interactions of antibacterial and antifungal agents with statins

\begin{tabular}{|c|c|c|}
\hline $\begin{array}{c}\text { Antimicrobial-Statin } \\
\text { Interaction }\end{array}$ & $\begin{array}{c}\text { Increase in Statin } \\
\text { AUC (times its } \\
\text { original value) }\end{array}$ & Package Insert Recommendation \\
\hline $\begin{array}{c}\text { Clarithromycin with } \\
\text { atorvastatin }\end{array}$ & 3.5 & Atorvastatin maximum=20 mg/day \\
\hline Clarithromycin with simvastatin & 11 & Contraindicated \\
\hline Erythromycin with simvastatin & 4 & Contraindicated \\
\hline Clarithromycin with pravastatin & 2 & Pravastatin maximum=40 mg/day \\
\hline Erythromycin with pitavastatin & 3 & Pitavastatin maximum=1 mg/day \\
\hline Itraconazole with simvastatin & 19 & Contraindicated \\
\hline Itraconazole with lovastatin & 15 & Contraindicated \\
\hline Itraconazole with atorvastatin & $2.5-3.3$ & Atorvastatin maximum=20 mg/day \\
\hline Fluconazole with fluvastatin & 2 & Fluvastatin maximum=20 mg/day \\
\hline Posaconazole with simvastatin & $7-8$ & Contraindicated \\
\hline
\end{tabular}

antifungal agents were included. In addition, the package inserts of statins and the precipitating antibacterial/antifungal agents were checked for manufacturer recommendations.

For macrolides, a systematic search identified two $[13,14]$ observational studies and five [15-19] PK studies, and a manual search identified one additional PK study [20]. For daptomycin, systematic and manual searches identified four PK studies [21-24] and one [25] observational study, respectively. For rifampin, a systematic search identified three PK studies [26-28] assessing the impact of single dose and four PK studies [29-32] assessing the impact of multiple doses. Eight [33-40] PK studies were identified for azole antifungals.

\section{Discussion}

\section{Statins interactions with macrolides}

CYP3A4 is inhibited strongly by clarithromycin, moderately by erythromycin, and weakly by azithromycin [41-44].Unlike azithromycin, clarithromycin and erythromycin also inhibit OATP1B [45].In a population-based cohort of older adults, concomitant administration of clarithromycin and/or erythromycin with statins was associated with a higher risk of adverse events compared to concomitant administration of azithromycin with statins $[13,14]$.

Clarithromycin increase the AUC of atorvastatin by up to 3.5 times its original value, while erythromycin increases it by 1.3 times its original value [15-17].In contrast, azithromycin has no impact on the AUC of atorvastatin.22 The manufacturer of atorvastatin recommends against a dosage exceeding $20 \mathrm{mg} /$ day when co-administered with clarithromycin [16,17].Clarithromycin and erythromycin should be avoided with simvastatin because they increase the AUC of simvastatin acid by 11 times and 4 times their original values, respectively $[7,16,18,42]$. A similar effect is expected with lovastatin given that it is a major CYP3A4 substrate [46].

The manufacturer of pitavastatinrecommends against exceeding a dosage of $1 \mathrm{mg} /$ day when co-administered with erythromycin because erythromycin increases the AUC of pitavastatin by 3 times its original value [47]. The manufacturer of pravasatin recommends against exceeding a dosage of $40 \mathrm{mg} /$ day when co-administered with clarithromycin because clarithromycin results in a doubling of the pravastatin AUC [12,16,42]. Rosuvastatin and fluvastatin could be considered for use as safer alternative statins because the AUC of neither drug increases when co-administered with erythromycin $[9,10,19,20,48]$. Azithromycin could also be considered for use as a safer alternative macrolide when co-administered with statins.

\section{Statins interactions with daptomycin}

Both daptomycin and statins can cause skeletal muscle toxicity and require $\mathrm{CK}$ monitoring; concomitant administration may increase this risk [49]. A case of rhabdomyolysis and AKI has been reported with the co-administration of daptomycin with simvastatin; in this case, serum creatinine and CK normalized after stopping daptomycin [50]. The prescribing information for daptomycin recommends considering suspending statin during treatment with daptomycin [49]. To date, studies have not found a higher risk of adverse outcomes with concomitant administration; however, these studies are retrospective and could be underpowered [21-25].

McConnell et al.'s study compared 233 patients receiving daptomycin (53 with statins and 180 without statins) and did not find a statistically significant difference in frequency of CK elevation $(5.7 \%$ vs $1.1 \%$, respectively; $p=0.08$ ) [25]. Bland et al's study compared 220 patients receiving daptomycin (49 with statins vs 171 without statins) and did not find statistically significant differences in frequencies of myalgia ( $6.1 \%$ vs $2.9 \%$, respectively; $p=0.38$ ), CK levels of $>1,000 \mathrm{U} /$ liter ( $10.2 \%$ vs $5.3 \%$, respectively; $p=0.32$ ), or therapy discontinuation due to $\mathrm{CK}$ elevations with concurrent myalgia $(6.1 \%$ vs $3.5 \%$, respectively; $p=0.42$ ). [21]. Berg et al.'s study compared 498 patients receiving daptomycin (63 with statins and 384 without statins) and did not find a statistically significant difference in frequency of CK elevation (Hazard Ratio, 0.44; 95\% Confidence Interval, 0.14- 1.40; $p$ $=0.17$ ) [22]. Golightly et al.'s study compared 157 patients receiving statins (52 with daptomycin and 105 without daptomycin) and did not find a statistically significant difference in frequency of CK elevation ( $9 \%$ vs $21 \%$, respectively; $p=0.135$ ) [23].Parra-Ruiz et al.'s study compared 104 patients receiving daptomycin (52 with statins and 105 without statins) and did not find a statistically significant difference in frequency of CK levels $>1000 \mathrm{U} / \mathrm{L}$ ( $8 \%$ vs $10 \%$, respectively; $p=0.746$ ) [24].

\section{Statins interactions with rifampin}

Rifampin is an inducer of CYP450, particularly 3A4 and 2C9, and some drug transporters, while it is an inhibitor of other transporters such as OATP1B1/3 [51-53]. The interaction of atorvastatin with rifampin is interesting because it is time-dependent and caused by a dual interaction mechanism. One dose of concomitant rifampin resulted in an increase in the AUC of atorvastatin, pitavastatin, and pravastatin by 7 times, 5.8 times, and 2.3 times their original values, respectively [26-28]. This effect can be explained by rapid OATP1B1/3 inhibition by rifampin [26]. In contrast, 5 days of rifampin nonsimultaneous administration resulted in an $80 \%$ decrease in the AUC of atorvastatin [29]. This is due to slower CYP450 induction by rifampin. However, there was no reduction in atorvastatin AUC with simultaneous administration of rifampin, which is why the manufacturer recommends simultaneous rather than delayed administration of atorvastatin after rifampin administration [6]. In other studies, concomitant administration of rifampin decreased the AUC ofsimvastatin acid, pravastatin, fluvastatin, and pitavastatin by $90 \%, 50 \%, 30 \%$, and $30 \%$ respectively $[9.11,30,31]$.A small study looked at the pharmacokinetics of rosuvastatin when co-administered with rifampin. However, the response was variable and the dose used was $450 \mathrm{mg} /$ day rather than the common dose of $600 \mathrm{mg} /$ day [32]. Further studies are needed to better understand the impact of rifampin on rosuvastatin.

\section{Statins interactions with azole antifungals}

Itraconazole is a strong CYP3A4 inhibitor and increases the AUC of lovastatin acid and simvastatin acid by 15-20 times and 19 
times their original values, respectively $[33,34,54]$. Therefore, the coadministration of itraconazole with these statins is contraindicated $[7,8]$. Itraconazole also increases the AUC of atorvastatin by $2.5-3.3$ times its original value; therefore, the manufacturer of atorvastatin recommends not exceeding a dosage of $20 \mathrm{mg} /$ day when coadministered with itraconazole [6,35,36]. The AUCs of pitavastatin, fluvastatin, pravastatin, and rosuvastatin are not significantly affected by co-administration with itraconazole $[11,30,33,36,37,54]$.

Fluconazole is a strong inhibitor of CYP2C9 and potentially CYP2C19 and therefore approximately doubles the AUC of fluvastatin. Given this effect, the manufacturer of fluvastatin recommends not exceeding a dosage of $20 \mathrm{mg} /$ day when co-administered with fluconazole $[9,38]$. The AUCs of pravastatin and rosuvastatin are not significantly affected by co-administration with fluconazole; however, caution is advised with rosuvastatin,especially with polymorphism of CYP2C9 $[38,39]$. In addition, as fluconazole is a moderate CYP3A4 inhibitor, it may increase the AUC of lovastatin, simvastatin, and atorvastatin; thus, caution when co-administering fluconazole with these statins is advised [55-57].

Posaconazole is a strong CYP3A4 inhibitor and increases the AUC of simvastatin acid by approximately 7-8 times its original value [40]. Per prescribing information, its administration is contraindicated with simvastatin, lovastatin, and atorvastatin [58]. Ketoconazole is a strong CYP3A4 inhibitor and its concomitant administration with simvastatin and lovastatin is also contraindicated [59]. However, it does not affect fluvastatin and rosuvastatin significantly $[48,60]$.

\section{Statins interactions with fusidic acid}

Statins should be avoided during and until 7 days post-therapy with systemic fusidic acid [61]. Although the exact mechanism is still unknown, it seems the interaction can be explained partially by inhibition of CYP3A and drug transporters BCRP and OATP1B1 [62].

\section{Conclusion}

This review discussed clinically relevant interactions of statins with antibacterial and antifungal agents based on the pharmacokinetic properties of object and precipitant drugs, pharmacokinetic studies, observational studies, and manufacturer recommendations. The pharmacokinetic differences among statins should be considered when evaluating drug interactions with antimicrobial agents. Some statins require dose adjustments, discontinuation during antimicrobial therapy, changing antimicrobial therapies, or simple monitoring. Clinicians should combine current knowledge and recommendations with their clinical judgment to determine the best intervention for each patient; however, we provided this summary to help guide decisionmaking when encountering statin-antimicrobial drug interactions.

\section{References}

1. Law M, Rudnicka AR (2006) Statin safety: a systematic review. Am J Cardiol97: 52C-60C.[Crossref]

2. Neuvonen PJ, Niemi M, Backman JT (2006) Drug interactions with lipid-lowering drugs: mechanisms and clinical relevance. ClinPharmacolTher80: 565-581.[Crossref]

3. Kalliokoski A, Niemi M (2009) Impact of OATP transporters on pharmacokinetics. $\mathrm{Br}$ J Pharmacol158: 693-705.[Crossref]

4. Christians U, Jacobsen W, Floren LC (1998) Metabolism and drug interactions of 3-hydroxy-3-methylglutaryl coenzyme A reductase inhibitors in transplant patients: are the statins mechanistically similar? PharmacolTher 80:1-34. [Crossref]

5. Chatzizisis YS, Koskinas KC, Misirli G, Vaklavas C, Hatzitolios A, et al. (2010) Risk factors and drug interactions predisposing to statin-induced myopathy: implications for risk assessment, prevention and treatment. Drug Saf 33: 171-187. [Crossref]

6. Lipitor (atorvastatin oral tablet) product information. New York, NY: Pfizer, March 2015.

7. Zocor (simvastatin oral tablet) product information. Whitehouse Station, NJ: Merck $\&$ Co, Feb 2015.

8. Mevacor (lovastatin oral tablet) product information. Whitehouse Station, NJ: Merck \& Co, Feb 2014.

9. Lescol (fluvastatin oral tablet) product information. East Hanover, NJ: Novartis Pharmaceuticals Corporation, Oct 2012.

10. Crestor (rosuvastatin oral tablet) product information. Wilmington, DE: AstraZeneca Pharmaceuticals LP, May 2016.

11. Livalo (pitavastatin oral tablet) product information. Montgomery, AL: Kowa Pharmaceuticals America, Oct 2013.

12. Pravachol (pravastatin oral tablet) product information. Princeton, NJ: Bristol-Myers Squibb Company, Oct 2012.

13. Patel AM, Shariff S, Bailey DG, Juurlink DN, Gandhi S, et al. (2013) Statin toxicity from macrolide antibiotic coprescription: a population-based cohort study. Ann Intern Med 158: 869-876.[Crossref]

14. Li DQ, Kim R, McArthur E, Fleet JL, Bailey DG, et al. (2015) Risk of adverse events among older adults following co-prescription of clarithromycin and statins not metabolized by cytochrome P450 3A4. CMAJ 187: 174-180.17. [Crossref]

15. Siedlik PH, Olson SC, Yang BB, Stern RH (1999) Erythromycin coadministration increases plasma atorvastatin concentrations. J ClinPharmacol39:501-504. [Crossref]

16. Jacobson TA (2004) Comparative pharmacokinetic interaction profiles of pravastatin, simvastatin, and atorvastatin when coadministered with cytochrome P450 inhibitors. Am J Cardiol94:1140-1146.[Crossref]

17. Amsden GW, Kuye O, Wei GC (2002)A study of the interaction potential of azithromycin and clarithromycin with atorvastatin in healthy volunteers. J ClinPharmacol42: 444 449.[Crossref]

18. Kantola T, Kivistö KT, Neuvonen PJ (1998) Erythromycin and verapamil considerably increase serum simvastatin and simvastatin acid concentrations. ClinPharmacolTher64 177-182.[Crossref]

19. Cooper KJ, Martin PD, Dane AL, Warwick MJ, Raza A, et al. (2003) The effect of erythromycin on the pharmacokinetics of rosuvastatin. Eur J ClinPharmacol59: 51-56. [Crossref]

20. Aberg J, Eriksson U, Fager G (1997) Effects of erythromycin on plasma fluvastatinlevels a pharmacokinetic study. Atherosclerosis 134:118A.

21. Bland CM, Bookstaver PB, Lu ZK, Dunn BL, Rumley KF, et al. (2014) Musculoskeletal safety outcomes of patients receiving daptomycin with $\mathrm{HMG}-\mathrm{CoA}$ reductase inhibitors. Antimicrob Agents Chemother 58:5726-5731. [Crossref]

22. Berg ML, Estes LL, Dierkhising RA, Curran B, Enzler MJ (2014) Evaluation of impact of statin use on development of CPK elevation during daptomycin therapy. Ann Pharmacother48: 320-327.[Crossref]

23. Golightly LK, Barber GR, Barron MA, Page RL 2nd (2013) Statins and daptomycin: safety assessment of concurrent use and evaluation of drug interaction liability. Drug Metabol Drug Interact 28: 49-58. [Crossref]

24. Parra-Ruiz J, Dueñas-Gutiérrez C, Tomás-Jiménez C, Linares-Palomino JP, GarridoGomez J, et al. (2012) Safety analysis of high dose ( $>6 \mathrm{mg} / \mathrm{kg} /$ day) daptomycin in patients with concomitant statin therapy. Eur J ClinMicrobiol Infect Dis 31:1771-1774. [Crossref]

25. McConnell HL, Perris ET, Lowry C, Lodise T, Patel N (2014) Effect of Concomitan 3-Hydroxy-3-Methyl-Glutaryl-CoA Reductase Inhibitor Therapy on Creatine Phosphokinase Levels and Mortality Among Patients Receiving Daptomycin: Retrospective Cohort Study. Infect Dis Ther 3:225-233.

26. Lau YY, Huang Y, Frassetto L, Benet LZ (2007) effect of OATP1B transporter inhibition on the pharmacokinetics of atorvastatin in healthy volunteers. ClinPharmacolTher81: 194-204.[Crossref]

27. Chen Y, Zhang W, Huang WH, Tan ZR, Wang YC, et al. (2013) Effect of a singledose rifampin on the pharmacokinetics of pitavastatin in healthy volunteers. Eur $J$ ClinPharmacol69: 1933-1938.[Crossref]

28. Deng S, Chen XP, Cao D, Yin T, Dai ZY, et al. (2009) Effects of a concomitant single oral dose of rifampicin on the pharmacokinetics of pravastatin in a two-phase, 
randomized, single-blind, placebo-controlled, crossover study in healthy Chinese male subjects. ClinTher 31:1256-1263. [Crossref]

29. Backman JT, Luurila H, Neuvonen M, Neuvonen PJ (2005) Rifampin markedly decreases and gemfibrozil increases the plasma concentrations of atorvastatin and its metabolites. ClinPharmacolTher 78:154-167. [Crossref]

30. Kyrklund C, Backman JT, Kivistö KT, Neuvonen M, Laitila J, et al. (2000) Rifampin greatly reduces plasma simvastatin and simvastatin acid concentrations. ClinPharmacolTher68: 592-597.[Crossref]

31. Kyrklund C, Backman JT, Neuvonen M, Neuvonen PJ (2004) Effect of rifampicin on pravastatin pharmacokinetics in healthy subjects. $\mathrm{Br} J$ ClinPharmacol57: 181-187. [Crossref]

32. Zhang W, Deng S, Chen XP, Zhou G, Xie HT, et al. (2008) Pharmacokinetics of rosuvastatin when coadministered with rifampicin in healthy males: a randomized single-blind, placebo-controlled, crossover study. ClinTher 30:1283-1289. [Crossref]

33. Kivistö KT, Kantola T, Neuvonen PJ (1998) Different effects of itraconazole on the pharmacokinetics of fluvastatin and lovastatin. Br JClinPharmacol46: 49-53.[Crossref]

34. Neuvonen PJ, Kantola T, Kivistö KT (1998) Simvastatin but not pravastatin is very susceptible to interaction with the CYP3A4 inhibitor itraconazole. ClinPharmacolTher63: 332-341.[Crossref]

35. Kantola T, Kivistö KT, Neuvonen PJ (1998) Effect of itraconazole on the pharmacokinetics of atorvastatin. ClinPharmacolTher64: 58-65.[Crossref]

36. Mazzu AL, Lasseter KC, Shamblen EC, Agarwal V, Lettieri J, et al. (2000) Itraconazole alters the pharmacokinetics of atorvastatin to a greater extent than either cerivastatin or pravastatin. ClinPharmacolTher68: 391-400.[Crossref]

37. Cooper KJ, Martin PD, Dane AL, Warwick MJ, Schneck DW, et al. (2003) Effect of itraconazole on the pharmacokinetics of rosuvastatin. ClinPharmacolTher73: 322-329. [Crossref]

38. Kantola T, Backman JT, Niemi M, Kivistö KT, Neuvonen PJ (2000) Effect of fluconazole on plasma fluvastatin and pravastatin concentrations. Eur J ClinPharmacol56: 225229. [Crossref]

39. Cooper KJ, Martin PD, Dane AL, Warwick MJ, Schneck DW, et al. (2002) The effect of fluconazole on the pharmacokinetics of rosuvastatin. Eur J ClinPharmacol58: 527531.[Crossref]

40. Krishna G, Ma L, Prasad P, Moton A, Martinho M, et al. (2012) Effect of posaconazole on the pharmacokinetics of simvastatin and midazolam in healthy volunteers. Expert Opin Drug MetabToxicol8: 1-10.[Crossref]

41. Zithromax (azithromycin oral tablet) product information. New York, NY: Pfizer, May 2015.

42. Biaxin (clarithromycin oral tablet) product information. North Chicao, IL: AbbVie, May 2016.

43. E.E.S (erythromycin oral granule) product information. Atlanta, GA: Arbor Pharmaceuticals, Feb 2012.

44. Ohno Y, Hisaka A, Suzuki H (2007) General framework for the quantitative prediction of CYP3A4-mediated oral drug interactions based on the AUC increase by coadministration of standard drugs. ClinPharmacokinet 46: 681-696.[Crossref]

45. Seithel A, Eberl S, Singer K, Auge D, Heinkele G, et al. (2007) The influence of macrolide antibiotics on the uptake of organic anions and drugs mediated by OATP1B1 and OATP1B3. Drug MetabDispos 35: 779-786. [Crossref]
46. Hisaka A, Kusama M, Ohno Y, Sugiyama Y, Suzuki H (2009)A proposal for a pharmacokinetic interaction significance classification system (PISCS) based on predicted drug exposure changes and its potential application to alert classifications in product labeling. ClinPharmacokinet 48:653-666. [Crossref]

47. Elsby R, Hilgendorf C, Fenner K (2012) Understanding the critical disposition pathways of statins to assess drug-drug interaction risk during drug development: it's not just about OATP1B1. ClinPharmacolTher92: 584-598.[Crossref]

48. Scripture CD, Pieper JA (2001) Clinical pharmacokinetics of fluvastatin ClinPharmacokinet40: 263-281.[Crossref]

49. Cubicin (daptomycin for injection) product information. Lexington, MA: Cubist Pharmaceuticals, Sep 2015.

50. Odero RO, Cleveland KO, Gelfand MS (2009)Rhabdomyolysis and acute renal failure associated with the co-administration of daptomycin and an HMG-CoA reductase inhibitor. J AntimicrobChemother 63:1299-1300.

51. Burman WJ, Gallicano K, Peloquin C (1999) Therapeutic implications of drug interactions in the treatment of human immunodeficiency virus-related tuberculosis. Clin Infect Dis 28: 419-429.[Crossref]

52. Burman WJ, Gallicano K, Peloquin C (2001) Comparative pharmacokinetics and pharmacodynamics of the rifamycinantibacterials. ClinPharmacokinet40: 327-341. [Crossref]

53. Oswald S, Giessmann T, Luetjohann D, Wegner D, Rosskopf D, et al. (2006) Disposition and sterol-lowering effect of ezetimibe are influenced by single-dose coadministration of rifampin, an inhibitor of multidrug transport proteins. ClinPharmacolTher 80:477485. [Crossref]

54. Neuvonen PJ, Jalava KM (1996) Itraconazole drastically increases plasma concentrations of lovastatin and lovastatin acid. ClinPharmacolTher60: 54-61. [Crossref]

55. Shaukat A, Benekli M, Vladutiu GD, Slack JL, Wetzler M, et al. (2003) Simvastatinfluconazole causing rhabdomyolysis. Ann Pharmacother37: 1032-1035.[Crossref]

56. Hazin R, Abuzetun JY, Suker M, Porter J (2008) Rhabdomyolysis induced by simvastatin-fluconazole combination. J Natl Med Assoc 100: 444-446.[Crossref]

57. Kahri J, Valkonen M, Bäcklund T, Vuoristo M, Kivistö KT (2005) Rhabdomyolysis in a patient receiving atorvastatin and fluconazole. Eur J ClinPharmacol60: 905-907. [Crossref]

58. Noxafil (posaconazole oral suspension) product information. Titisville, NJ: Janssen Pharmaceuticals, Feb 2014

59. Nizoral (ketoconazole oral tablets) product information. Whitehouse Station, NJ: Merck \& Co, Nov 2015

60. Cooper KJ, Martin PD, Dane AL, Warwick MJ, Raza A, et al. (2003) Lack of effect of ketoconazole on the pharmacokinetics of rosuvastatin in healthy subjects. $\mathrm{Br} J$ ClinPharmacol55: 94-99.[Crossref]

61. Fucidin (sodium oral tablets and powder for injection) product information. Queensland, Australia: Leo Pharma, Dec 2015.

62. Gupta A, Harris JJ, Lin J, Bulgarelli JP, Birmingham BK, et al. (2016) Fusidic acid inhibits hepatic transporters and metabolic enzymes: potential cause of clinical drugdrug interaction observed with statin coadministration. Antimicrob Agents Chemother 60:5986-5994. [Crossref]

Copyright: (C2017 Eljaaly K. This is an open-access article distributed under the terms of the Creative Commons Attribution License, which permits unrestricted use, distribution, and reproduction in any medium, provided the original author and source are credited. 